\title{
Temporal trends and variation in out-of- pocket expenditures and patient cost sharing: evidence from a Chinese national survey 2011-2015
}

Vicky Mengqi Qin ${ }^{1 *}$ (D), Yuting Zhang ${ }^{2}$, Kee Seng Chia ${ }^{1}$, Barbara McPake ${ }^{3}$, Yang Zhao ${ }^{3}$, Emily S. G. Hulse ${ }^{4}$ Helena Legido-Quigley ${ }^{1}$ and John Tayu Lee ${ }^{3,5}$

\begin{abstract}
Objectives: This study aims to examine: (1) temporal trends in the percentage of cost-sharing and amount of outof-pocket expenditure (OOPE) from 2011 to 2015; (2) factors associated with cost-sharing and OOPE; and (3) the relationships between province-level economic development and cost-sharing and OOPE in China.

Setting: A total of 10,316 adults aged $\geq 45$ years from China followed-up from 2011 to 2015 were included in the analysis. We measured two main outcome variables: (1) patient cost sharing, measured by the percentage of OOPE as total healthcare expenditure, and (2) absolute amount of OOPE.

Results: Based on self-reported data, we did not find substantial differences in the percentage of cost sharing, but a significant increase in the absolute amount of OOPE among the middle-aged and older Chinese between 2011 and 2015. The percentage of cost-sharing was considerably higher for outpatient than inpatient care, and the majority paid more than $80 \%$ of the total cost for prescription drugs. Provinces with higher GDP per capita tend to have lower cost-sharing and a higher OOPE than their counterparts, but the relationship for OOPE became insignificant after adjusting for individual factors.
\end{abstract}

Conclusion: Reducing out-of-pocket expenditure and patient cost sharing is required to improve financial protection from illness, especially for those with those with chronic conditions and reside in less developed regions in China. Ongoing monitoring of financial protection using data from various sources is warranted.

Keywords: User fees, Cost- sharing, Out-of-pocket payment, Geographical variation, Socioeconomic disparity, China

\footnotetext{
* Correspondence: ma.qin@u.nus.edu

'Saw Swee Hock School of Public Health, National University of Singapore, Singapore, Singapore

Full list of author information is available at the end of the article
}

(c) The Author(s). 2021 Open Access This article is licensed under a Creative Commons Attribution 4.0 International License, which permits use, sharing, adaptation, distribution and reproduction in any medium or format, as long as you give appropriate credit to the original author(s) and the source, provide a link to the Creative Commons licence, and indicate if changes were made. The images or other third party material in this article are included in the article's Creative Commons licence, unless indicated otherwise in a credit line to the material. If material is not included in the article's Creative Commons licence and your intended use is not permitted by statutory regulation or exceeds the permitted use, you will need to obtain permission directly from the copyright holder. To view a copy of this licence, visit http://creativecommons.org/licenses/by/4.0/ The Creative Commons Public Domain Dedication waiver (http://creativecommons.org/publicdomain/zero/1.0/) applies to the data made available in this article, unless otherwise stated in a credit line to the data. 


\section{Strengths and limitations of this study}

- This is the first longitudinal study to measure the trend of and variation in patient cost-sharing and OOPE in China.

- User fees were self-reported by the respondents, which may be subject to recall bias.

- User fees in this study only reflected the general cost burden from formal health care services; therefore, user fees from informal care services were not captured.

\section{Key findings}

- There were no substantial reduction in patient cost-sharing for outpatient and inpatient services, but the amount of out-of-pocket expenditure (OOPE) continued to rise during 2011-2015

- Despite universal health insurance coverage, patient cost-sharing was still high among the middle-aged and older Chinese: 84.0\% for outpatient care and 69.2\% for inpatient care in 2011; and $80.8 \%$ vs $62.2 \%$ in 2015 . The majority of patients paid more than $80 \%$ of the total cost for prescription drugs when visiting outpatient or inpatient care.

- Several patient-level characteristics affected cost-sharing and OOPE, including insurance status, age, education, household economic status and number of chronic conditions.

Cost-sharing was lower for those with insurance compared to those without insurance.

- Provinces with higher GDP per capita had lower cost-sharing than provinces with lower GDP per capita, but no significant difference was found in the amount of OOPE after controlling for individual-level factors.

\section{Introduction}

Protection against catastrophic levels of health spending as a result of illness has been a key goal of health systems in many countries $[1,2]$. User fees, defined as direct payment at the point of seeking care paid by patients, remain the primary source of health care financing in many low-and middle-income countries [3-6]. Access to health care is inversely related to income and socioeconomic status, where wealthier groups have better access to high-quality health care than the poorer groups [7, 8].

In China, almost the entire population (more than 95\% in 2013) is covered by one of the three social health insurance schemes: the New Rural Cooperative Medical Scheme (NCMS), the Urban Resident Basic Medical Insurance (URBMI), and the Urban Employee Basic Medical Insurance (UEBMI). Insured patients' user fees include deductibles (i.e., fees paid out-of-pocket below deductible thresholds), copayment (i.e., a certain percentage applied to the fees beyond deductible and below reimbursement ceiling), and patient payment above the reimbursement ceiling (i.e., fees beyond upper limit of copayment is paid out-of-pocket, which should be at least six times of the average income). The design of user fees vary by social health insurance scheme $[1,9$, 10].

At the end of 2015, the Chinese government announced the decision to integrate URBMI and NCMS as the Urban-Rural Resident Medical Insurance Scheme. This integration has enabled a further extension of funding pools and narrowing disparities in access to health care services and medications that existed between different insurance schemes [11]. The three social health insurance schemes are designed to target different populations. The NCMS targets the registered rural population; the URBMI and UEBMI target the urban nonemployed residents and employees, respectively. UEBMI generally provides more comprehensive service coverage (including both outpatient and inpatient services) and lower cost-sharing compared with the other two schemes [12]. In addition, user fees for the same health insurance scheme can vary significantly across provinces due to fiscal capacity and priority setting of local governments [13]. Official statistics reported that per capita OOPE increased more than three folds in the past two decades (2000-2019), i.e., from 85 Yuan to 290 Yuan for outpatient care, and from 3083 Yuan to 9848 Yuan for inpatient care [14].

Two recent multli-country studies of universal health coverage of over 100 countries found that China has a higher incidence of catastrophic health expenditure compared to countries with similar economic development levels $[15,16]$. Low level of benefit coverage and fragmented social health insurance schemes could be the reason for the high incidence of catastrophic health expenditure, in particular among the rural, poorer and sicker population [17]. It is worth noted that the increasing demand of health care and forgone timely treatment among the rapidly aging population has also driven up OOPE [18-20]. In addition, spending on medications has become a major component of total health expenditure $(41.9 \%$ in 2010$)$ [21]. Thus, improving financial protection is crucial for health system strengthening in China, and the Chinese government has set an ambitious target to substantially reduce patient cost-sharing (i.e. the percentage of out-of-pocket payment in total health expenditure) from $60 \%$ in 2001 to $25 \%$ by 2030 [22].

The literature on the provincial level variation in user fees is relatively sparse in China [13, 23-25]. A recent cross-sectional analysis of the key parameters of different health insurance programs found that cost-sharing varies 
significantly by insurance schemes in China [23]. However, there is no longitudinal study to comprehensively document the individual and contextual factors associated with user fees and how user fees change over time. The answers to two research questions remain unclear: (1) How do user fees change over time in China? (2) What are factors associated with the variation in user fees in China? Understanding these questions could provide policies for social health insurance reforms in China. Using the longitudinal data from 2011 to 2015 of the China Health And Retirement Longitudinal Study (CHARLS), we examine: (1) trends in cost-sharing and OOPE among middle-aged and older adults in China;

(2) socioeconomic factors associated with user fees, and

(3) the relationships between province-level economic development and user fees in China.

\section{Methods}

Data

We used the longitudinal data from the China Health And Retirement Longitudinal Study (CHARLS) conducted in 2011, 2013, and 2015. CHARLS adopted the multi-stage stratified probability proportional to size sampling method at baseline. CHARLS had collected a nationally representative sample aged 45 years and above from 150 counties in 28 provinces. At baseline in 2011, 17,708 respondents $(80.5 \%$ response rate) were interviewed, and 13,565 (76.6\% of baseline sample) were followed up concurrently for three waves [26]. We identified 10,316 respondents, after removing ineligible respondents aged 45 years and below or with missing values in covariates.

\section{Measurements and variables}

We measured user fees regarding: patient cost- sharing, defined as the ratio of out-of-pocket payment (OOPE) in total health care spending, and the actual amount of OOPE (in Chinese Yuan) [27]. We calculated them for outpatient and inpatient services separately. In addition, we also calculated user fees for prescription drugs which have been a major component of health spending in China [21]. We examined the association between socioeconomic determinants, geographic region, and user fees.

Respondents who sought outpatient care last month or inpatient care last year were asked: "What was the total cost of this visit (or hospitalisation), including both treatment and medication cost (or fees paid to the hospital)?", and "How much did you pay out of pocket, after reimbursement from insurance (for the total costs of hospitalisation)?" Similarly, respondents were asked: "What was the total medication cost for this visit, including prescription you received?", and "How much will you eventually pay out of pocket for the medications from this visit, including prescriptions you received?" for outpatient and inpatient settings, respectively. If there was no cost or respondents did not pay for the visits or medications, then patient cost-sharing was denoted as 0 . Likewise, if the respondents further reported that the outpatient or inpatient visits were not covered by any insurance, then cost-sharing was denoted as 1 .

Socioeconomic indicators that may vary user fees were included in the analysis as independent variables, including: health insurance type (UEBMI, URBMI, NCMS, others, without insurance), location (rural, urban), gender, age $(45-54,55-64,65-74, \geq 75)$, marital status (single/divorced/widowed, married/cohabitated), number of self-reported doctor-diagnosed NCDs at the individual level (none, 1 type of NCD, 2 types of NCDs, $\geq 3$ types of NCDs), working status (working, retired, nonworking), household economic status (the most deprived, deprived, middle, affluent and the most affluent), education (elementary school and below, secondary school, college and above) and time (year) [23, 28, 29]. Respondents with both social health insurance schemes and other types of health insurance (e.g. private insurance, government medical insurance (Gong Fei) and other supplementary insurance) were coded as "others". We included 13 types of NCDs that are available in CHARLS for the calculation: hypertension, dyslipidaemia, diabetes, cancer, chronic lung disease, liver disease, heart disease, stroke, chronic kidney disease, digestive disease, mental disorders, arthritis and asthma. Household economic status was defined based on quintiles of yearly per capita household consumption. Per capita household consumption was based on a relative approach by comparing yearly per capita household consumption to the median value at the city level to reduce bias from imbalance economic development across regions [30]. We also explored the relationship between user fees and economic development. We identified and ranked economic development at the provincial level based on their GDP per capita: low, < 4300 US\$; middle, 4300-12,000 US\$; high, $\geq 12,000$ US\$ ( 1 USD = $6.2 \mathrm{CNY}$ in 2014). The cut-off points for grouping provinces were referred to the country classifications from the World Bank [31].

\section{Statistical analysis}

We measured socioeconomic and provincial inequality in user fees using a series of regression-based methods [32]. We adopted a four-level random intercept linear regression model to explore the association between socioeconomic determinants and user fees, and to control for individual heterogeneity and measure external effects. OOPE was log-transformed in regression to allow for a more intuitive interpretation of regression coefficients as percentage changes in OOPE. The multilevel model accounted for hierarchical nature of the CHARLS 
data, with individuals at the first level, and community, city and province at the second, third and fourth level, respectively.

Therefore, cost-sharing (denoted as $\mathrm{Y}_{\mathrm{ijk \textrm {k }}}$ ) of individual $\mathrm{i}$, living in community $\mathrm{j}$ of city $\mathrm{k}$ in province $\mathrm{l}$ in time $\mathrm{t}$, given his/her sociodemographic characteristics can be described as follows:

$$
\begin{aligned}
& \mathrm{Y}_{\mathrm{ijkl}}= \beta_{0}+\beta * \mathrm{X}_{\mathrm{ijkl}}+\beta_{\text {time }, i} * \mathrm{t}_{\mathrm{ijkl}}+\mathrm{v}_{\mathrm{k}}+\mathrm{u}_{\mathrm{jk}}+\mathrm{e}_{\mathrm{ijk}} \\
&+\mathrm{g}_{\mathrm{ijk}} \\
& \mathrm{v}_{\mathrm{k}} \sim N\left(0, \sigma_{\mathrm{v}}^{2}\right) \\
& \mathrm{u}_{\mathrm{jk}} \sim N\left(0, \sigma_{\mathrm{u}}^{2}\right) \\
& \mathrm{e}_{\mathrm{ijk}} \sim N\left(0, \sigma_{\mathrm{e}}^{2}\right) \\
& \mathrm{g}_{\mathrm{ijk} \mathrm{l}} \sim N\left(0, \sigma_{\mathrm{g}}^{2}\right)
\end{aligned}
$$

Where $Y_{\mathrm{ijkl}}$ is the predicted cost- sharing, $\beta_{0}$ is the mean cost-sharing across participants, $\mathrm{X}_{\mathrm{ijk} \mathrm{l}}$ represents the vector of all independent variables that were adjusted for in the analysis with $\beta$ as the fixed effect, $\beta_{\text {time }, i}$ counted for the time effect, $v_{k}, u_{i k}, e_{i j k}$ and $g_{i j k l}$ represent the random effect of province, city, community, and individual respectively, assuming an independent and normal distribution with zero mean and constant variances $\left(\sigma_{\mathrm{v}}^{2}, \sigma_{\mathrm{u}}^{2}, \sigma_{\mathrm{e}}^{2}, \sigma_{\mathrm{g}}^{2}\right)$.

We also measured the variance of cost-sharing attributable to each level of the multilevel model by calculating variance partition coefficients (VPC). We excluded outliers with an extremely high value of health expenditures (i.e. $>30,000$ Yuan for outpatient $(0.08 \%$ among the respondents without lost-to-follow-up), before the calculation. To allow comparison over time, OOPE reported in 2011 and 2013 were converted to 2015 price using the gross domestic product (GDP) deflator according to the World Bank [33]. Adjusted coefficient ( $\beta$ ) and 95\% confidence intervals $(\mathrm{CI})$ were presented for multilevel models, with $p<0.05$ taken as statistically significant. All statistical analyses were conducted using STATA 16.0.

\section{Results}

We analysed panel data from 10,316 respondents observed in 2011, 2013, and 2015. Table 1 summaries the sociodemographic characteristics of the respondents. At baseline, the majority of the respondents were female $(51.1 \%)$, aged $55-64$ years $(38.9 \%)$, residing in rural areas (58.7\%), currently working (71.4\%), and attained elementary education or below (64.6\%) in 2015. More than 65\% of the respondents had at least one type of diagnosed NCD. More than $94 \%$ of participants were enrolled in at
Table 1 Sociodemographic characteristics of sample at baseline

\begin{tabular}{lc}
\hline & N (\%) \\
\hline Health insurance & $602(5.8)$ \\
No insurance & $8072(73.7)$ \\
NCMS & $470(5.5)$ \\
URBMI & $922(12.1)$ \\
UEBMI & $250(2.9)$ \\
Others & \\
Location & $3575(41.3)$ \\
Urban & $6741(58.7)$ \\
Rural & \\
PCE & $1170(694)$ \\
Lowest 20\% & $2697(1164)$ \\
Lower 20\% & $4500(1801)$ \\
Middle 20\% & $7548(2797)$ \\
Higher 20\% & $14,260(17328)$ \\
Highest 20\% & \\
Employment & $252(2.5)$ \\
Not working & $2417(26.1)$ \\
Retired & $7647(71.4)$ \\
Working &
\end{tabular}

\section{Education}

Elementary or below

$6861(64.6)$

Secondary school

$3314(33.4)$

College and above

$141(2)$

Age (years)

45-54

3921 (38.9)

55-64

4150 (38.9)

65-74

$1818(17.8)$

$\geq 75$

$427(4.4)$

Gender

Male

5086 (48.9)

Female

$5230(51.1)$

Marital

single or divorce or widowed

$955(9.8)$

married or cohabitated

$9361(90.2)$

\section{Comorbidity}

None

$3450(34.2)$

1 NCD

3244 (31.3)

2 NCDs

$1997(18.9)$

$\geq 3 \mathrm{NCDs}$

1625 (15.5)

N

10,316

Note:

-All results are weighted to account for complex survey design. -Abbreviation: UEBMI Urban Employee Basic Medical Insurance, URBMI Urban Resident Basic Medical Insurance, NCMS New Rural Cooperative Medical Scheme, Others government health care, private medical insurance and others, NCD Non-communicable disease, PCE Per capita expenditure (Chinese Yuan)

-median PCE of each wealth group was displayed with standard deviation in parentheses 
least one of the insurance schemes, with the majority insured by NCMS (73.7\%).

\section{The trend in user fees 2011-2015}

Overall, there was no substantial reduction in patient cost-sharing between 2011 and 2015. However, the amount of OOPE continued to rise within the 4 year period (from an average of 457 Yuan to 860 Yuan for outpatient, and from 4861Yuan to 5747 Yuan for inpatient services).

Patient cost-sharing was higher for outpatient than inpatient care (e.g. $82 \%$ vs $67 \%$ in 2011 and $80 \%$ vs $63 \%$ in 2015). The majority of the patients had to pay more than $80 \%$ of the total cost of prescription drugs when visiting outpatient or inpatient care.

Across the three major types of social health insurance schemes, participants enrolled in UEBMI had a lower cost-sharing compared with participants enrolled in URBMI and NCMS. Participants enrolled in urban insurance (UEBMI or URBMI) had a higher OOPE than those insured by NCMS in rural areas (Table 2). From 2011 to 2015, the differences in absolute amount of the OOPE across three social health insurance schemes for outpatient services narrowed, but the differences in percentage of cost sharing increased. In inpatient setting, both the differences in OOPE and cost sharing in general reduced. (Appendix Table 1).

Provinces with higher GDP per capita tend to have lower cost-sharing but higher OOPE for outpatient and inpatient care, compared with provinces with lower GDP per capita. (Appendix Figure 1 \& 2) Among provinces with high GDP per capita, the average cost-sharing was $73.1 \%$ (1341 Yuan) for outpatient visits, and 60.8\% (7641 Yuan) for inpatient visits in 2015. In comparison, the average cost-sharing was $80.7 \%$ (579 Yuan) for outpatient visits, and $67.0 \%$ (4505 Yuan) for inpatient visits among provinces with low GDP per capita. (Data not shown in tables).

\section{Percentage of cost-sharing Outpatient}

Outpatient cost-sharing was significantly lower among the insured respondents (regression coefficient $=-0.09$, $-0.09,-0.21,-0.28$, for NCMS, URBMI, UEBMI, and other health insurance respectively, $p<0.05)$ than the uninsured counterparts (Table 3). People who were in the older age group (regression coefficient $=-0.02$, $0.05,-0.08$, for those aged $55-64,65-74$, and 75 and above, $p<0.05$ ), retired (regression coefficient $=-0.09$, $p<0.05$ ), and had tertiary education (regression coefficient $=-0.16, \mathrm{p}<0.05$ ) had lower cost-sharing compared with those aged 45-54 years old, unemployed, and primary education or below, respectively. Outpatient costsharing was lower among respondents from regions with high GDP per capita compared to respondents from regions with low GDP per capita (regression coefficient = $-0.09, p<0.05)$. Outpatient cost-sharing was not associated with gender, marital status, household economic status, and number of NCDs. There was no significant change in outpatient cost-sharing during 2011 and 2015 $(p>0.05)$.

Likewise, people with insurance, tertiary education and older age also had lower cost-sharing of prescription drugs in outpatient setting compared to their counterparts without insurance, low education level, and aged 45-54 years. Respondents from regions with high GDP per capita (regression coefficient $=-0.05, p=0.05$ ) had significantly lower cost-sharing of prescription drugs than those from regions with low GDP per capita. Other sociodemographic covariates such as household economic status, employment status, and number of NCDs were not associated with outpatient cost-sharing of prescription drugs $(p>0.05)$.

\section{Inpatient}

Inpatient cost-sharing was significantly lower among respondents with health insurance (regression coefficient = $-0.28,-0.32,-0.45,-0.51$, for NCMS, URBMI, UEBMI, and other health insurance respectively, $p<$ 0.05). Respondents who were female (regression coefficient $=0.03, \mathrm{p}<0.05$ ), married (regression coefficient $=$ $0.04, p<0.05$ ), and resided in rural area (regression coefficient $=0.05, p<0.05$ ) had higher level of cost-sharing than their counterparts. Respondents who were aged between 55 and 64, 65-74, and 75 and older had a lower level of cost-sharing (regression coefficient = $0.03,-0.05,-0.08, \mathrm{p}<0.05)$, compared with those aged 45-54 years. The level of inpatient cost-sharing was lower in the year 2013 (regression coefficient =$0.10, \mathrm{p}<0.05$ ) and 2015 (regression coefficient $=-$ $0.09, \mathrm{p}<0.05)$, compared with the year 2011. Costsharing for inpatient services was not significantly associated with education level, employment status, household economic status, number of NCDs, and regional economic development.

Similarly, inpatient cost-sharing of prescription drugs was lower among people with insurance, aged 75 and above, had tertiary education compared to those without insurance, aged 45-54, and had primary education or below, respectively. Inpatient cost-sharing of prescription drugs was not significantly different with regard to employment status, household economic status, location and provincial economic development $(p>0.05)$.

\section{Amount of OOPE Outpatient}

Table 4 shows that the amount of OOPE for outpatient visits was lower among respondents insured by UEBMI 
Table 2 Patient Out-of-pocket Expenditure and Cost-sharing by Health Insurance schemes during 2011-2015

Insurance status
Outpatient
Total cost
OOPE for doctor visits ${ }^{\mathrm{a}}$
Cost sharing
Amount of OOPE for prescription drug
Cost sharing for prescription drugs
Seek outpatient care observation
Inpatient
Total cost
OOPE for hospitalization ${ }^{\mathrm{a}}$
Cost sharing
OOPE for prescription drugs ${ }^{\mathrm{b}}$
Cost sharing for prescription drugs
Seek inpatient care observation

\section{Outpatient}

Total cost
OOPE for doctor visits ${ }^{a}$
COst sharing ${ }^{a}$
Amount of OOPE for prescription drug ${ }^{b}$
Cost sharing for prescription drugs ${ }^{b}$
Seek outpatient care observation
Total cost
OOPE for hospitalization ${ }^{a}$
Cost sharing
OOPE for prescription drugs
Cost sharing for prescription drugs ${ }^{b}$
Seek inpatient care observation

$753(647,859)$
$522(441,602)$
$0.76(0.69,0.83)$
$358(305,411)$
$0.86(0.82,0.91)$
3958

$\begin{array}{ccccccc}677(571,782) & 567(290,844) & 540(442,638) & 771(488,1054) & 1031(663,1399) & 1731(622,2839) & <0.01 \\ 457(388,525) & 478(188,768) & 431(348,514) & 545(322,767) & 475(309,642) & 719(307,1131) & <0.01 \\ 0.82(0.79,0.85) & 0.9(0.83,0.98) & 0.87(0.84,0.89) & 0.7(0.53,0.88) & 0.68(0.58,0.77) & 0.57(0.44,0.7) & <0.01 \\ 298(259,338) & 387(120,655) & 251(221,281) & 324(177,471) & 423(274,572) & 473(23,923) & <0.01 \\ 0.88(0.85,0.91) & 0.97(0.93,1) & 0.92(0.9,0.94) & 0.74(0.55,0.93) & 0.78(0.69,0.87) & 0.68(0.54,0.82) & <0.01 \\ 3286 & & & & & & \end{array}$

$7971(7008,8935)$

$4861(4245,5477)$
$5550(4073$ 7027)

$0.67(0.64,0.7)$

$3668(3131,4205)$

$0.85(0.82,0.87)$

1560

$$
\begin{aligned}
& 4150(3107, \\
& 5193)
\end{aligned}
$$

$0.91(0.83,1)$

2884 (1976, 3791)

$0.9(0.81,0.99)$

$6903(5699$,
$8108)$

$7494(4878,10$, 110)

4732 (4081, 5382)

$0.74(0.71,0.77)$

3674 (3023, 4325)

$0.86(0.84,0.89) \quad 0.89(0.85,0.94)$

2013

$10,082(7258,12$ 906)

$6508(4087,8929)$

$653(351,955)$

$578(330,826)$

$0.96(0.92,1)$

$717(608,826)$

$548(466,631)$

$0.85(0.84,0.87)$

$294(133,455)$

$364(299,429)$

$0.94(0.85,1.03) \quad 0.93(0.92,0.94)$

\section{Inpatient}

$0.62(0.59,0.65) \quad 0.99(0.97,1.01) \quad 0.65(0.62,0.67)$

$5419(2951,7888)$

$$
4944(3614
$$$$
\text { 6273) }
$$

$0.83(0.81,0.85)$

$0.99(0.97,1.01) \quad 0.84(0.82,0.86)$

2385

\section{Outpatient}

Total cost

OOPE for doctor visits ${ }^{a}$

Cost sharing $^{a}$

Amount of OOPE for prescription drug (Yuan) $)^{b}$

Cost sharing for prescription drugs ${ }^{b}$

Seek outpatient care observation

\section{$1279(1076,1482) \quad 1744(600,2888) \quad 1094(898$,}

$$
\text { 1290) }
$$

$860(705,1015) \quad 937(430,1444) \quad 801(640,961)$

$0.8(0.77,0.82) \quad 0.89(0.84,0.93) \quad 0.84(0.82,0.86)$

$375(309,441) \quad 350(167,534) \quad 316(264,368)$

$0.85(0.83,0.88) \quad 0.88(0.83,0.93) \quad 0.9(0.88,0.92)$ 3754
$888(490,1286)$

$546(236,855)$

$0.61(0.4,0.82)$

$418(208,628)$

$0.78(0.51,1.04)$

$$
\text { 578) }
$$

$11,672(8219,15$

$$
\text { 124) }
$$

$$
\text { 472) }
$$

$0.66(0.56,0.76)$

$20,367(-4290,45$ 023)

$0.82(0.76,0.87)$

\section{5}

$1169(668,1670)$

$842(482,1201)$

$0.88(0.83,0.93)$

$462(318,607)$

$0.91(0.87,0.95)$

$818(524,1111)$

$445(244,647)$

$0.51(0.35,0.68)$

$335(237,433)$

$0.67(0.58,0.76)$

$0.48(0.4,0.55)$

$0.8(0.74,0.85)$

$$
(0.74,0.85)
$$

$562(1121,2002)$
20,955(-3563, 45,
$5454(3896,7012)$

4594 (3044, 6145)

$825(190,1460)<0.01$

$245(117,372)<0.01$

$0.49(0.36,0.62)<0.01$

$204(91,317)<0.01$

$0.61(0.48,0.73)<0.01$

$10,722(7868,13,<0.01$ 575)

$6535(1762,11,<0.01$ 308)

$0.4(0.29,0.5)<0.01$

$5198(2122,8274) \quad 0.0037$

$0.79(0.68,0.89)<0.01$

$813(530,1096) \quad 2381(-388,5150)<0.01$

$0.61(0.53,0.69) \quad 0.51(0.39,0.64)<0.01$

$478(252,704) \quad 797(135,1459) \quad<0.01$

$0.69(0.61,0.76) \quad 0.61(0.49,0.73) \quad<0.01$ 
Table 2 Patient Out-of-pocket Expenditure and Cost-sharing by Health Insurance schemes during 2011-2015 (Continued)

\begin{tabular}{|c|c|c|c|c|c|c|c|}
\hline Insurance status & Total & None & NCMS & URBMI & UEBMI & Other & $\begin{array}{c}P \\
\text { value }\end{array}$ \\
\hline \multicolumn{8}{|c|}{ Inpatient } \\
\hline Total cost & $\begin{array}{c}9757(8846,10 \\
668)\end{array}$ & $\begin{array}{c}7207(5633 \\
8782)\end{array}$ & $\begin{array}{l}8194(7487 \\
8901)\end{array}$ & $\begin{array}{c}10,073(8117,12 \\
030)\end{array}$ & $\begin{array}{c}14,826(11,850,17 \\
802)\end{array}$ & $\begin{array}{c}8731(5716,11 \\
746)\end{array}$ & $<0.01$ \\
\hline OOPE for hospitalization ${ }^{a}$ & $5747(5228,6266)$ & $\begin{array}{c}4578(3458 \\
5698)\end{array}$ & $\begin{array}{c}5605(5038 \\
6172)\end{array}$ & $6046(4708,7385)$ & $6562(5021,8103)$ & $4285(1885,6685)$ & $<0.01$ \\
\hline Cost sharing ${ }^{a}$ & $0.63(0.61,0.65)$ & $0.9(0.84,0.96)$ & $0.67(0.65,0.69)$ & $0.59(0.56,0.63)$ & $0.44(0.4,0.47)$ & $0.43(0.29,0.56)$ & $<0.01$ \\
\hline OOPE for prescription drugs ${ }^{b}$ & $4418(3922,4915)$ & $\begin{array}{c}3822(2790 \\
4853)\end{array}$ & $\begin{array}{c}4206(3702 \\
4710)\end{array}$ & $4298(3072,5525)$ & $5374(3728,7021)$ & $3126(895,5356)$ & $<0.01$ \\
\hline Cost sharing for prescription drugs ${ }^{b}$ & $0.84(0.82,0.86)$ & $0.93(0.88,0.99)$ & $0.86(0.84,0.87)$ & $0.83(0.78,0.88)$ & $0.77(0.71,0.83)$ & $0.75(0.59,0.9)$ & $<0.01$ \\
\hline Seek inpatient care observation & 2590 & & & & & & \\
\hline $\begin{array}{l}\text { Note: } \\
\text { The currency unit of total cost and OO } \\
\text { OOPE and cost sharing were presente } \\
\text { These tables were generated based o } \\
\text { OOPE = out-of-pocket expenditure } \\
P \text { value }<0.01 \text { indicates that the mean } \\
\text { on Kruskal-Wallis test. } \\
\text { Cross-sectional sampling weight was } \\
\text { OOPE in } 2011 \text { and } 2013 \text { were convert } \\
\text { andicates the total cost shared or pai } \\
\text { b Indicates only the total cost for pres }\end{array}$ & $\begin{array}{l}\text { in this table is Chin } \\
\text { llowed by } 95 \% \mathrm{Cl} \text { ir } \\
\text { e full sample of yea } \\
\text { lef cost-sharing w } \\
\text { ied for each year. } \\
2015 \text { price based } \\
\text { patients, including } \\
\text { tion drugs shared o }\end{array}$ & $\begin{array}{l}\text { se Yuan. } \\
\text { the parenthsis. } \\
\text { wave so as to tr } \\
\text { on statistically diff } \\
\text { prescription drug }\end{array}$ & $\begin{array}{l}\text { ack the national } \\
\text { erent between th }\end{array}$ & ree social health in & rance schemes at & $\%$ significance leve & based \\
\hline
\end{tabular}

(regression coefficient $=-0.34, p<0.05)$ and "other insurance" including private and government-funded insurance (regression coefficient $=-1.17, \quad \mathrm{p}<0.05$ ) compared to those without insurance. Older age groups (regression coefficient $=-0.13,-0.21$ and -0.48 for age group 55-64, 65-74 and 75 and above respectively, $p<$ 0.05 ) and tertiary education (regression coefficient $=-$ $0.80, p<0.05)$ was associated with less OOPE, compared to people aged 45-54 years and who had primary education or below respectively. Respondents from households with the most affluent economic status spent more on outpatient OOPE compared to those from the worst economic status (regression coefficient $=0.39, p<0.05$ ). Respondents who were married (coefficient $=0.21, \mathrm{p}<$ 0.05 ) and had more NCDs (coefficient $=0.27,0.42,0.46$, for people had two and more than two types of NCDs, $\mathrm{p}<0.05)$ spent higher OOPE than their counterparts who were male, single, and without diagnosed NCDs respectively. OOPE was higher in year 2013 (regression coefficient $=0.21, p<0.05$ ) and 2015 (regression coefficient $=0.45, \mathrm{p}<0.05$ ), compared with year 2011. Outpatient OOPE were also not associated with employment status, education, location, and regional economic development.

Outpatient OOPE of prescription drugs were also lower among respondents insured by UEBMI and "other insurance", being in older age group groups than the uninsured group and those aged 45-54 years. Respondents from the most affluent households (coefficient $=0.36$, $p<0.05$ ) and who had more NCDs (coefficient $=0.43$, for people who had two and more than two types of
NCDs, $p<0.05)$ spent a higher amount of OOPE compared their counterparts. No significant difference was found for outpatient OOPE of prescription drugs with regards to gender, marital status, employment status, location, and provincial economic development.

\section{Inpatient}

OOPE for inpatient services did not significantly differ by the type of social health insurance compared to those without any insurance. However, people covered by "other insurance" such as private insurance (regression coefficient $=-1.10, p<0.05$ ) spent less OOPE than those without insurance. People in the older age groups spent less for inpatient OOPE compared to those aged 45-54 years (regression coefficient $=-0.43,-0.74$, for $65-74$ and 75 and above, respectively, $p<0.05$ ). Respondents who were married (regression coefficient $=0.48, p<0.05$ ) and had the most affluent household economic status (regression coefficient $=0.76, p<0.05$ ) spent more on inpatient OOPE compared to those single and with the most deprived household economic status. Respondents from provinces with middle and high GDP per capita spent more on OOPE (regression coefficient $=0.24,0.65$, for middle and high GDP per capita respectively $p<$ $0.05)$ compared to those from provinces with low GDP per capita. Inpatient OOPE was not associated with gender, employment status, education, number of NCDs, and location.

Respondents who were in the older age group (regression coefficient $=-0.35,-0.49$, for aged $65-74$ and 75 and above respectively, $p<0.05$ ), employed (regression 
Table 3 Determinants of patient cost-sharing for outpatient and inpatient services from multilevel regression analysis

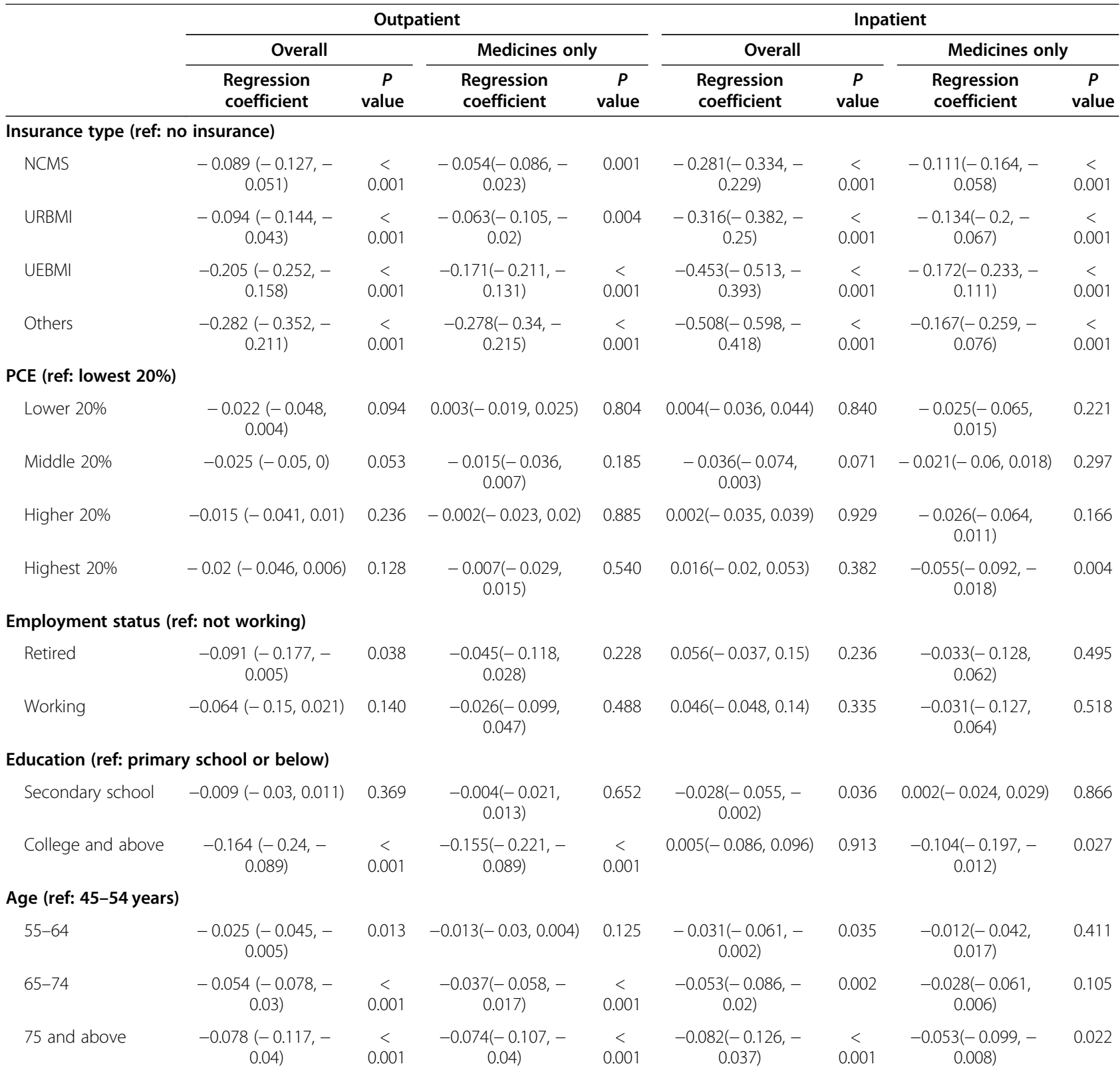

Gender (ref: male)

Female $\quad 0.008(-0.008,0.025)$

\section{Marital (ref: single or divorce or widowed)}

Married or

cohabitated

$0.004(-0.019,0.027) \quad 0.716$

\section{Comorbidity (ref: none)}

1 NCD
2 NCDs
$>2$ NCDs

$$
0.004(-0.023,0.031)
$$

0.763

$0.005(-0.019,0.028)$

0.694

$0.031(-0.01,0.071)$

0.138

0.995

$0.011(-0.013,0.034)$

0.364

$0.015(-0.024,0.054) \quad 0.452$

$0.976 \quad 0.007(-0.03,0.044) \quad 0.696$
$0.702 \quad O(-0.023,0.022)$
$0.021)$ 
Table 3 Determinants of patient cost-sharing for outpatient and inpatient services from multilevel regression analysis (Continued)

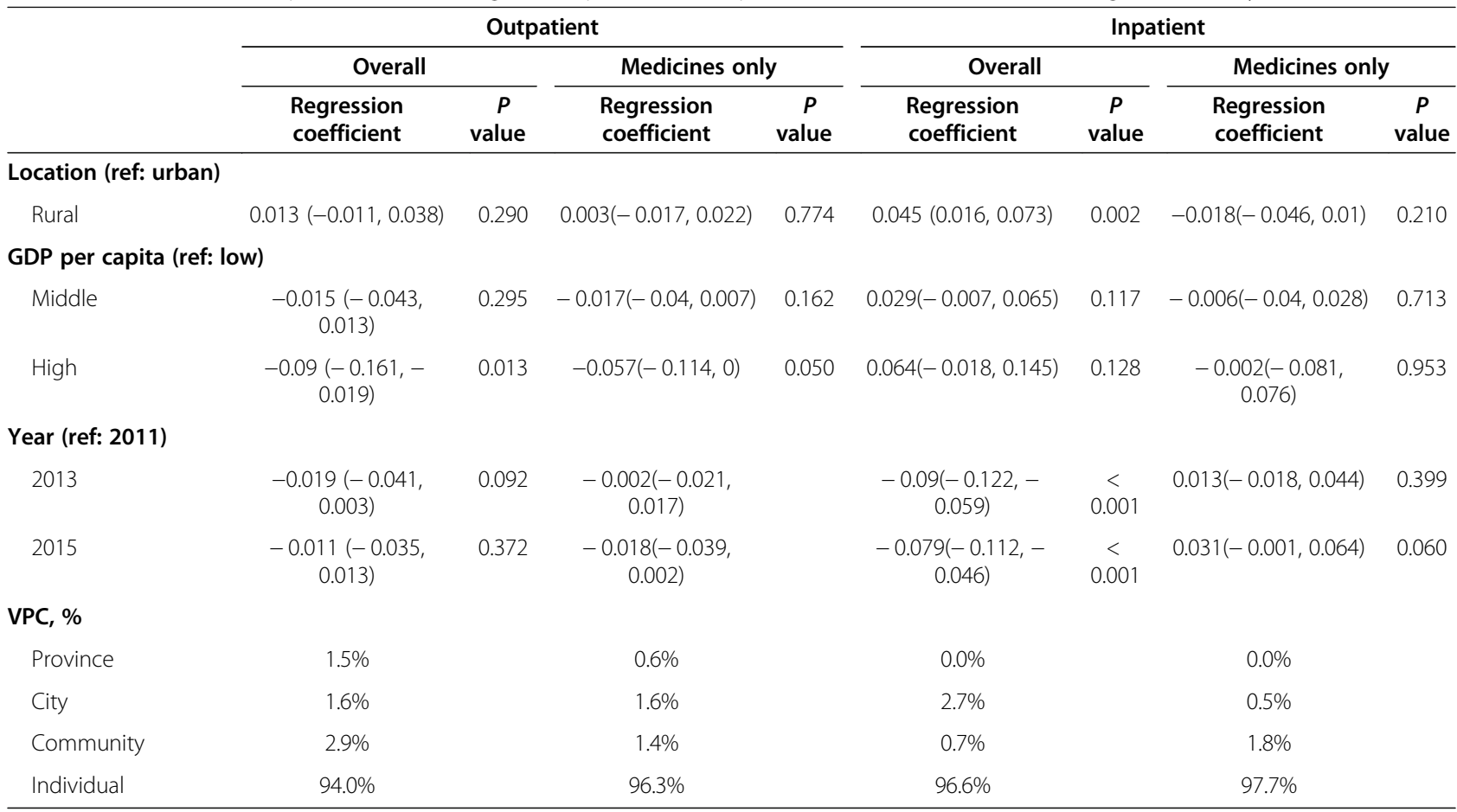

Note:

95\% $\mathrm{Cl}$ was displayed in parentheses after the regression coefficient

Respondents categorised in other insurance group were enrolled in insurance program other than the three major social health insurance, such as private insurance, government-funded insurance (Gong Fei) etc

Abbreviation: UEBMI Urban Employee Basic Medical Insurance, URBMI Urban Resident Basic Medical Insurance, NCMS New Rural Cooperative Medical Scheme, Others government health care, private medical insurance and others, PCE Per capita expenditure (Chinese Yuan), NCD Non-communicable disease, VPC Variance partition coefficient

A likelihood ratio test was conducted to compare the fully adjusted model with null model with only random intercept and multivariable linear model. Fully adjusted multilevel model is preferred $(P<0.01)$

coefficient $=-0.74, p<0.05)$, and had tertiary education (regression coefficient $=-0.80, p<0.05$ ) spent less on OOPE for prescription drugs during hospitalisation, compared to those aged 45-54 years and unemployed, respectively. People from the most affluent household (regression coefficient $=0.33, \mathrm{p}<0.05$ ) spent more on OOPE for prescription drugs than their counterparts from the most deprived household. OOPE for prescription drugs was significantly higher among respondents from regions with high GDP per capita compared to respondents from regions with low GDP per capita (regression coefficient $=0.61$, p $<$ 0.05). Inpatient OOPE for prescription drugs was not associated with gender, the number of NCDs, and location.

\section{Partitioning variations in user fees}

In the fully adjusted model for cost- sharing, $1.5 \%$ of the variation in outpatient cost-sharing comes from provinces, $1.6 \%$ from cities, $2.9 \%$ from communities within cities, and $94 \%$ lies within the community between individuals (Table 3). In inpatient settings, individuals accounted for $96.6 \%$ of the variation in cost-sharing, followed by 0.7 and $2.7 \%$ at the community and citylevel respectively.

Variation in outpatient OOPE was similar, with individuals accounted for $93.9 \%$ of the variation, followed by communities (1.8\%), cities (2.3\%) and provinces (2\%). Individual-level accounted for $96.4 \%$ of the variation in inpatient OOPE, with community, city and province-level accounted for 1.9, 0.6 and $1.1 \%$ (Table 4).

\section{Discussion}

\section{Principal findings}

Findings from the longitudinal dataset of 10,316 respondents aged 45 years and above in China, revealed no substantial reduction in the percentage of cost-sharing over time, but the amount of OOPE continued to rise. Costsharing and OOPE were lower among those insured 
Table 4 Determinants of the amount of OOPE for outpatient and inpatient services from multilevel regression analysis

\begin{tabular}{|c|c|c|c|c|c|c|c|c|}
\hline & \multicolumn{4}{|c|}{ Outpatient } & \multicolumn{4}{|c|}{ Inpatient } \\
\hline & \multicolumn{2}{|l|}{ Log of OOPE } & \multicolumn{2}{|c|}{$\begin{array}{c}\text { Log of OOPE for } \\
\text { Prescription drugs }\end{array}$} & \multicolumn{2}{|l|}{ Log of OOPE } & \multicolumn{2}{|c|}{$\begin{array}{c}\text { Log of OOPE for } \\
\text { Prescription drugs }\end{array}$} \\
\hline & $\begin{array}{l}\text { Regression } \\
\text { coefficient }\end{array}$ & $\begin{array}{c}P \\
\text { value }\end{array}$ & $\begin{array}{l}\text { Regression } \\
\text { coefficient }\end{array}$ & $\begin{array}{c}P \\
\text { value }\end{array}$ & $\begin{array}{l}\text { Regression } \\
\text { coefficient }\end{array}$ & $\begin{array}{c}P \\
\text { value }\end{array}$ & $\begin{array}{l}\text { Regression } \\
\text { coefficient }\end{array}$ & $\begin{array}{c}P \\
\text { value }\end{array}$ \\
\hline \multicolumn{9}{|c|}{ Insurance type (ref: no insurance) } \\
\hline NCMS & $\begin{array}{c}-0.094(-0.339 \\
0.152)\end{array}$ & 0.455 & $\begin{array}{l}-0.071(-0.295 \\
0.152)\end{array}$ & 0.532 & $-0.08(-0.427,0.267)$ & 0.652 & $\begin{array}{c}-0.065(-0.443 \\
0.314)\end{array}$ & 0.738 \\
\hline URBMI & $0.012(-0.312,0.337)$ & 0.941 & $0.111(-0.186,0.408)$ & 0.465 & $\begin{array}{c}-0.021(-0.454 \\
0.412)\end{array}$ & 0.925 & $\begin{array}{c}-0.065(-0.538 \\
0.408)\end{array}$ & 0.788 \\
\hline UEBMI & $\begin{array}{c}-0.338(-0.642,- \\
0.035)\end{array}$ & 0.029 & $\begin{array}{c}-0.266(-0.544 \\
0.011)\end{array}$ & 0.060 & $\begin{array}{c}-0.002(-0.401 \\
0.398)\end{array}$ & 0.993 & $0.035(-0.4,0.469)$ & 0.876 \\
\hline Others & $\begin{array}{c}-1.173(-1.626,- \\
0.72)\end{array}$ & $\begin{array}{c}< \\
0.001\end{array}$ & $\begin{array}{c}-1.333(-1.761,- \\
0.905)\end{array}$ & $\begin{array}{c}< \\
0.001\end{array}$ & $\begin{array}{c}-1.101(-1.686,- \\
0.516)\end{array}$ & $\begin{array}{c}< \\
0.001\end{array}$ & $\begin{array}{c}-0.347(-0.991 \\
0.298)\end{array}$ & 0.292 \\
\hline \multicolumn{9}{|l|}{ PCE (ref: lowest 20\%) } \\
\hline Lower 20\% & $\begin{array}{c}-0.141(-0.306 \\
0.024)\end{array}$ & 0.093 & $\begin{array}{c}-0.048(-0.199 \\
0.104)\end{array}$ & 0.538 & $0.115(-0.14,0.371)$ & 0.376 & $\begin{array}{c}-0.085(-0.366 \\
0.197)\end{array}$ & 0.556 \\
\hline Middle 20\% & $0.092(-0.07,0.254)$ & 0.264 & $0.081(-0.067,0.23)$ & 0.283 & $0.182(-0.066,0.43)$ & 0.151 & $0.097(-0.177,0.372)$ & 0.486 \\
\hline Higher 20\% & $0.112(-0.051,0.275)$ & 0.178 & $0.131(-0.018,0.28)$ & 0.085 & $0.493(0.255,0.732)$ & $\begin{array}{c}< \\
0.001\end{array}$ & $0.222(-0.04,0.484)$ & 0.097 \\
\hline Highest 20\% & $0.391(0.226,0.556)$ & $\begin{array}{c}< \\
0.001\end{array}$ & $0.361(0.21,0.512)$ & $\begin{array}{c}< \\
0.001\end{array}$ & $0.759(0.523,0.995)$ & $\begin{array}{c}< \\
0.001\end{array}$ & $0.326(0.066,0.586)$ & 0.014 \\
\hline \multicolumn{9}{|c|}{ Employment status (ref: not working) } \\
\hline Retired & $-0.156(-0.712,0.4)$ & 0.582 & $\begin{array}{c}-0.102(-0.611 \\
0.408)\end{array}$ & 0.696 & $0.202(-0.402,0.806)$ & 0.513 & $\begin{array}{c}-0.466(-1.127 \\
0.195)\end{array}$ & 0.167 \\
\hline Working & $\begin{array}{c}-0.444(-0.998 \\
0.109)\end{array}$ & 0.116 & $-0.407(-0.915,0.1)$ & 0.116 & $\begin{array}{l}-0.158(-0.765 \\
0.448)\end{array}$ & 0.608 & $\begin{array}{c}-0.739(-1.401,- \\
0.077)\end{array}$ & 0.029 \\
\hline \multicolumn{9}{|c|}{ Education (ref: primary school or below) } \\
\hline Secondary school & $-0.001(-0.13,0.128)$ & 0.988 & $0.011(-0.107,0.129)$ & 0.859 & $\begin{array}{c}-0.096(-0.271 \\
0.079)\end{array}$ & 0.282 & $0.071(-0.115,0.257)$ & 0.456 \\
\hline College and above & $\begin{array}{c}-0.802(-1.275,- \\
0.328)\end{array}$ & 0.001 & $\begin{array}{c}-0.488(-0.941,- \\
0.036)\end{array}$ & 0.035 & $\begin{array}{c}-0.056(-0.654 \\
0.541)\end{array}$ & 0.853 & $-0.78(-1.42,-0.14)$ & 0.017 \\
\hline \multicolumn{9}{|l|}{ Age (ref: $45-54$ years) } \\
\hline $55-64$ & $\begin{array}{c}-0.13(-0.257,- \\
0.002)\end{array}$ & 0.046 & $\begin{array}{l}-0.108(-0.224 \\
0.008)\end{array}$ & 0.069 & $\begin{array}{l}-0.163(-0.354 \\
0.027)\end{array}$ & 0.093 & $\begin{array}{c}-0.162(-0.368 \\
0.043)\end{array}$ & 0.121 \\
\hline $65-74$ & $\begin{array}{c}-0.208(-0.361,- \\
0.056)\end{array}$ & 0.008 & $\begin{array}{c}-0.145(-0.285,- \\
0.005)\end{array}$ & 0.042 & $\begin{array}{c}-0.425(-0.64,- \\
0.21)\end{array}$ & $\begin{array}{c}< \\
0.001\end{array}$ & $\begin{array}{c}-0.356(-0.588,- \\
0.124)\end{array}$ & 0.003 \\
\hline 75 and above & $\begin{array}{c}-0.482(-0.727,- \\
0.237)\end{array}$ & $\begin{array}{c}< \\
0.001\end{array}$ & $\begin{array}{c}-0.381(-0.608,- \\
0.154)\end{array}$ & 0.001 & $\begin{array}{c}-0.74(-1.033,- \\
0.447)\end{array}$ & $\begin{array}{c}< \\
0.001\end{array}$ & $\begin{array}{c}-0.498(-0.814,- \\
0.181)\end{array}$ & 0.002 \\
\hline \multicolumn{9}{|l|}{ Gender (ref: male) } \\
\hline Female & $0.036(-0.071,0.143)$ & 0.508 & $0.021(-0.077,0.119)$ & 0.680 & $\begin{array}{c}-0.129(-0.273 \\
0.016)\end{array}$ & 0.081 & $\begin{array}{c}-0.106(-0.261 \\
0.048)\end{array}$ & 0.177 \\
\hline \multicolumn{9}{|c|}{ Marital (ref: single or divorce or widowed) } \\
\hline $\begin{array}{l}\text { Married or } \\
\text { cohabitated }\end{array}$ & $0.212(0.066,0.357)$ & 0.004 & $0.075(-0.059,0.209)$ & 0.273 & $0.482(0.283,0.681)$ & $\begin{array}{c}< \\
0.001\end{array}$ & $0.145(-0.069,0.359)$ & 0.185 \\
\hline \multicolumn{9}{|c|}{ Comorbidity (ref: none) } \\
\hline $1 \mathrm{NCD}$ & $0.268(0.095,0.44)$ & 0.002 & $0.273(0.115,0.432)$ & 0.001 & $0.159(-0.103,0.421)$ & 0.233 & $0.114(-0.172,0.4)$ & 0.435 \\
\hline 2 NCDs & $0.417(0.243,0.59)$ & $\begin{array}{c}< \\
0.001\end{array}$ & $0.425(0.265,0.585)$ & $\begin{array}{c}< \\
0.001\end{array}$ & $0.071(-0.184,0.326)$ & 0.584 & $\begin{array}{c}-0.005(-0.283 \\
0.272)\end{array}$ & 0.971 \\
\hline$>2$ NCDs & $0.46(0.291,0.628)$ & $\begin{array}{c}< \\
0.001\end{array}$ & $0.431(0.276,0.586)$ & $\begin{array}{c}< \\
0.001\end{array}$ & $0.129(-0.111,0.369)$ & 0.291 & $0.021(-0.24,0.281)$ & 0.877 \\
\hline
\end{tabular}


Table 4 Determinants of the amount of OOPE for outpatient and inpatient services from multilevel regression analysis (Continued)

\begin{tabular}{|c|c|c|c|c|c|c|c|c|}
\hline & \multicolumn{4}{|c|}{ Outpatient } & \multicolumn{4}{|c|}{ Inpatient } \\
\hline & \multicolumn{2}{|l|}{ Log of OOPE } & \multicolumn{2}{|c|}{$\begin{array}{l}\text { Log of OOPE for } \\
\text { Prescription drugs }\end{array}$} & \multicolumn{2}{|l|}{ Log of OOPE } & \multicolumn{2}{|c|}{$\begin{array}{l}\text { Log of OOPE for } \\
\text { Prescription drugs }\end{array}$} \\
\hline & $\begin{array}{l}\text { Regression } \\
\text { coefficient }\end{array}$ & $\begin{array}{c}P \\
\text { value }\end{array}$ & $\begin{array}{l}\text { Regression } \\
\text { coefficient }\end{array}$ & $\begin{array}{c}P \\
\text { value }\end{array}$ & $\begin{array}{l}\text { Regression } \\
\text { coefficient }\end{array}$ & $\begin{array}{c}P \\
\text { value }\end{array}$ & $\begin{array}{l}\text { Regression } \\
\text { coefficient }\end{array}$ & $\begin{array}{c}P \\
\text { value }\end{array}$ \\
\hline \multicolumn{9}{|c|}{ Location (ref: urban) } \\
\hline Rural & $0.091(-0.061,0.243)$ & 0.240 & $0.049(-0.084,0.183)$ & 0.469 & $0.001(-0.184,0.187)$ & 0.988 & $\begin{array}{c}-0.349(-0.554,- \\
0.144)\end{array}$ & 0.001 \\
\hline \multicolumn{9}{|c|}{ GDP per capita (ref: low) } \\
\hline Middle & $-0.131(-0.312,0.05)$ & 0.157 & $\begin{array}{c}-0.104(-0.273 \\
0.064)\end{array}$ & 0.225 & $0.236(-0.004,0.476)$ & 0.054 & $0.146(-0.103,0.395)$ & 0.251 \\
\hline High & $\begin{array}{c}-0.208(-0.669 \\
0.254)\end{array}$ & 0.378 & $\begin{array}{c}-0.064(-0.498 \\
0.371)\end{array}$ & 0.773 & $0.649(0.094,1.204)$ & 0.022 & $0.605(0.011,1.2)$ & 0.046 \\
\hline \multicolumn{9}{|l|}{ Year (ref: 2011) } \\
\hline 2013 & $0.212(0.07,0.354)$ & 0.003 & $0.137(0.006,0.269)$ & 0.041 & $-0.096(-0.297,0.104)$ & 0.347 & $0.049(-0.174,0.272)$ & 0.664 \\
\hline 2015 & $0.447(0.292,0.602)$ & $\begin{array}{c}< \\
0.001\end{array}$ & $0.155(0.011,0.299)$ & 0.035 & $\begin{array}{c}-0.039(-0.252 \\
0.175)\end{array}$ & 0.723 & $0.136(-0.1,0.371)$ & 0.258 \\
\hline \multicolumn{9}{|l|}{ VPC, \% } \\
\hline Province & $2.0 \%$ & & $3.0 \%$ & & $1.1 \%$ & & $0.3 \%$ & \\
\hline City & $2.3 \%$ & & $2.4 \%$ & & $0.6 \%$ & & $0.0 \%$ & \\
\hline Community & $1.8 \%$ & & $1.1 \%$ & & $1.9 \%$ & & $3.8 \%$ & \\
\hline Individual & $93.9 \%$ & & $93.5 \%$ & & $96.4 \%$ & & $95.9 \%$ & \\
\hline
\end{tabular}

Note:

95\% Cl was displayed in parentheses after the regression coefficient

Respondents categorised in other insurance group were enrolled in insurance program other than the three major social health insurance, such as private insurance, government-funded insurance (Gong Fei) etc

Abbreviation: UEBMI Urban Employee Basic Medical Insurance, URBMI Urban Resident Basic Medical Insurance, NCMS New Rural Cooperative Medical Scheme, Others government health care, private medical insurance and others, OOPE Out-of-pocket expenditure, PCE Per capita expenditure (Chinese Yuan), VPC Variance partition coefficient

A likelihood ratio test was conducted to compare the fully adjusted model with null model with only random intercept and multivariable linear model. Fully adjusted multilevel model is preferred $(P<0.01)$

OOPE was log-transformed to normalise the distribution. Patients with zero OOPE were replaced by 1 for a mathematically meaningful log-transformation

than the uninsured group, with UEBMI than the other social health insurance schemes, and with private insurance than the social health insurance schemes. Provinces with higher GDP per capita in Beijing, Shanghai and Tianjin tend to have lower cost-sharing but higher OOPE than those provinces with lower GDP per capita in Yunnan, Guizhou, Gansu.

Several studies have examined level of user charges in China using different types of dataset, including administrative dataset and survey data. While our results are comparable with previous studies that were based on CHARLS dataset [34, 35], our findings on level of cost-sharing might be higher than other studies that reported 'reimbursement rate' in China [36]. Unlike reimbursement rate, which generally refers to the percentage of medical costs covered by health insurance for health services within the coverage of health insurance, our measurement of costsharing also include patient's out-of-pocket expenditure for health services that are outside of service coveage of the social health insurance programmes. It is why our estimates for levels of costsharing are not "identical" to the reimbursementrate reported in other studies.

Our findings showing patient cost-sharing was higher for the outpatient than inpatient visits, reflecting the better coverage for inpatient services in China. We found that people from households with higher economic status incurred a higher amount of OOPE from seeking treatment for their illness, which is similar to the conclusion from previous crosssectional studies [23, 25]. This is likely because those households with higher economic status have a higher demand of health care use and tend to visit highertiers of health care providers (such as seondary and tertiary hospitals) [37].

There are several important caveats of our study. Firstly, self-reported user fees in surveys may not be 
as accurate as health insurance claim data due to the expenditure categories used and the recall period. This limitation could led to higher recall bias and lower validity of the data compared to the administrative data [38, 39]. It is possible that levels of cost sharing or amount of OOPE estimated from this study will be different from those estimated based on different types of dataset such as administrative data [38]. Secondly, user fees in this study measured the general cost burden for seeking health care. Therefore, user fees for specific types of disease were not available. Thirdly, data on expenditure was only available among adults who visited outpatient care last month or inpatient care last year. It is possible that those who did not seek care have better health conditions and face different user fees. Generalisability of the results might also be exclusive of people aged 45 years and above who may have different patterns and determinants of user fees. Lastly, our findings of user fees only reflect the level of financial protection from formal health care services of hospital and clinics. Therefore, user fees from informal care (such as purchasing medicines over the counter) were not captured and beyond the scope of this study [40, 41].

\section{Policy implications}

One of the key focuses of current health financing reform in China is to reduce user fees, but few studies have examined this. We found that the percentage of cost-sharing for prescription drugs remained high nationwide. The high cost-sharing for outpatient raises concern for an aging population who need long-term access to outpatient care and medication treatment. Recent evidence shows that the introduction of a reimbursement for the outpatient cost of NCDs in NCMS has not reduced the incidence of catastrophic health expenditure effectively [42]. It is fundamental to further extend social health insurance to cover more health services. Targeted intervention to lower cost-sharing for long-term and chronic prescription drugs for people with NCDs is needed to enhance financial support of social health insurance [43]. Although the national policy reform of essential medicines reduced drug expenditure at inpatient settings, it has yet to significantly reduce drug expenditure at outpatient settings and for total health spending [44, 45]. Policies to broaden the benefits package of social health insurance, such as expanding the essential medicines list, should be prioritised [46]. While policies to lower mark-up for prescription drugs can reduce price, complementary financing mechanism such as government subsidies should be considered to counteract the income loss suffered by health care facilities and providers from drug sales
[21]. Effectively lowering cost-sharing is an essential strategy to make the needed health services accessible and affordable, that could reduce inequalities and yield more substantial and sustainable impacts on overall population health $[47,48]$. Although a few provinces have benefited from relatively low costsharing, high cost-sharing (higher than 30\%, a threshold considered as low level of financial protection) and increasing OOPE in most provinces, especially people from rural regions, should not be neglected [12].

Reducing patient user fees by expanding government subsidies alone is not sufficient to improve financial protection and access. It is also important to improve quality and efficiency of the healthcare system; that is, to reduce low-value care and promote high-value low cost medical care including primary care and preventive care $[49,50]$. The current health insurance schemes in China reimburse mainly on hospital care but not on outpatient primary care. In addition, the hospital-centric delivery system does not encourage the use of primary care $[36,51,52]$. China should continue to invest in strengthening primary care if it were to shift towards primary care-based demand for health care. This includes building primary care infrastructure, recruiting and training more quality primary care professionals, and educate the public on the value of preventive care services as a gatekeeper of health.

Future research is needed not only on examining the effect of reducing user fees on health outcomes, and different health benefits gained from user fees reduction from different types of health care, but also explore whether user fees inequality could mitigate with additional improvement in the process of healthcare delivery, such as quality and efficiency of primary care, and a shift to primary care-based health delivery system [43].

\section{Conclusion}

Despite near universal health insurance coverage, variation in user charges across proviences and population groups persist. A complementary reform of the fragmented social health insurance schemes and the integrated healthcare delivery system are required to improve financial protection and mitigate inequality from illness for vulnerable groups such as those with chronic conditions, especially in less developed regions in China. Ongoing monitoring of user fees using various source of datasets including national survey and administrative dataset is required to guide policy making at national and sub-national levels. 


\section{Appendix}

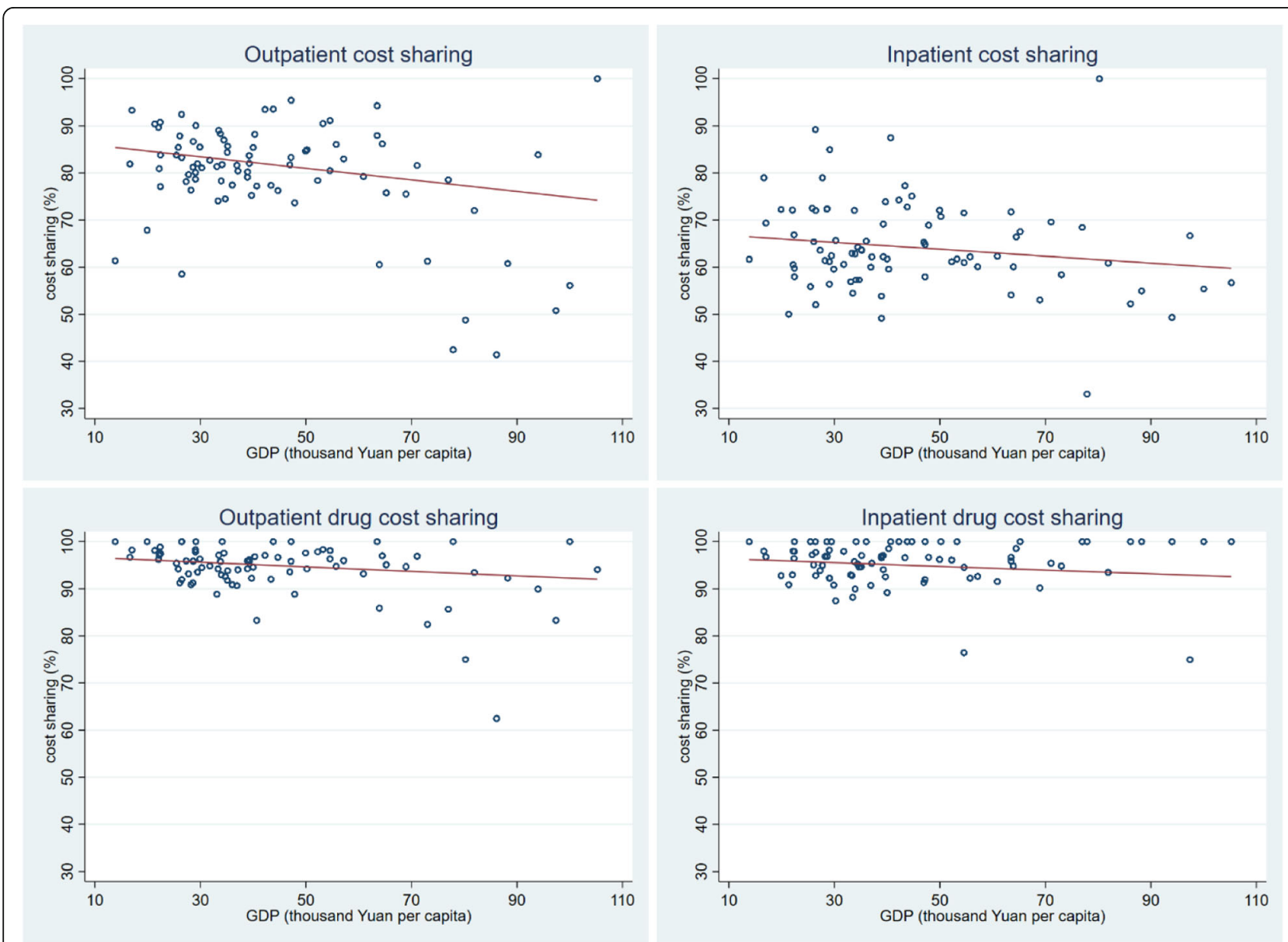

Fig. 1 Bivariate relationship between cost-sharing and economic development at the provincial level between 2011 and 2015 ( $n=84$ ). Note: Provincial GDP per capita data were extracted from China Statistical Yearbook 2016. Each province $(n=28)$ has three independent data points 


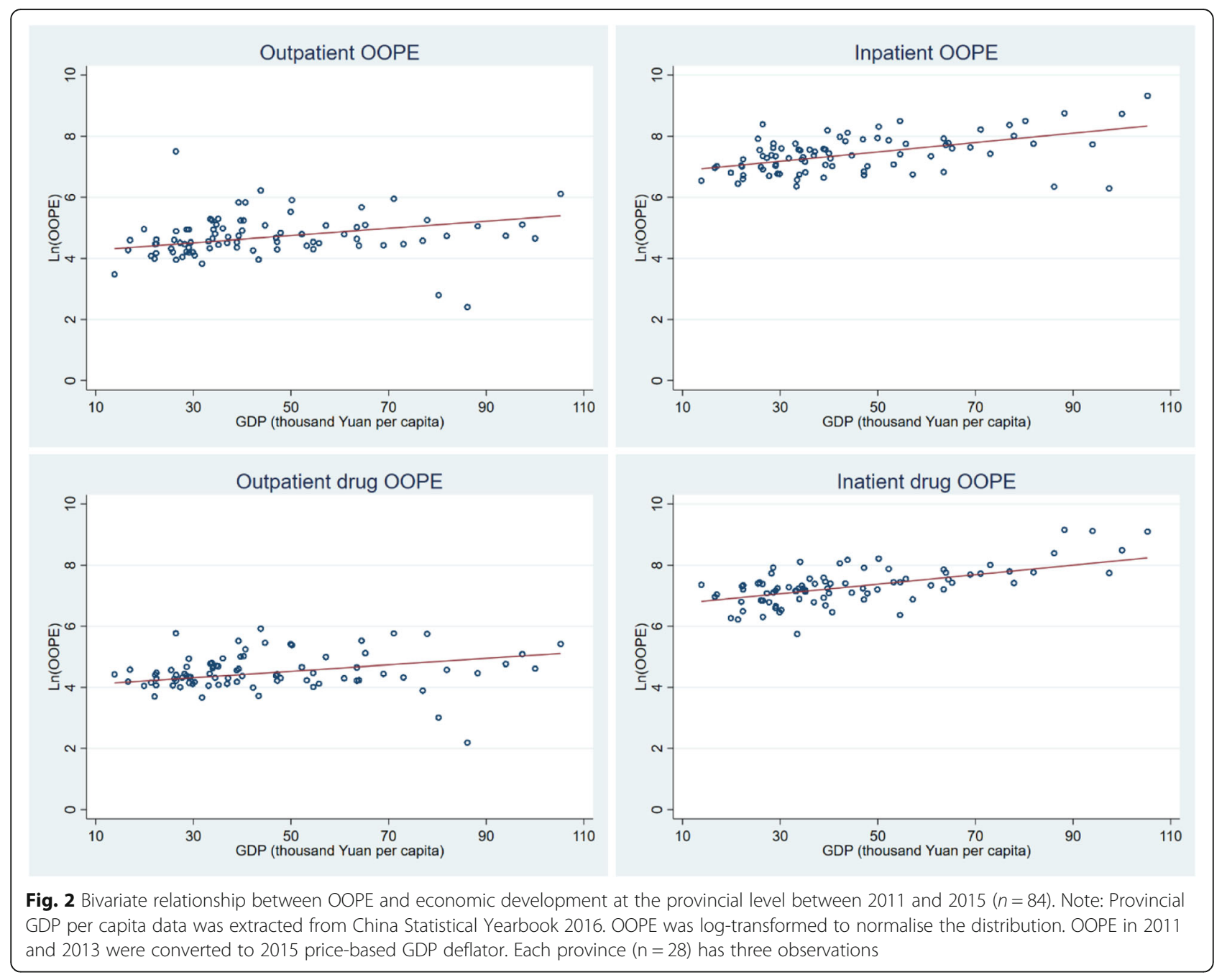


Table 5 Comparison of out-of-pocket expenditure and cost sharing across social health insurance schemes

\begin{tabular}{|c|c|c|c|c|}
\hline & UEBMI & Differece with URBMI & Differece with NCMS & Differece with non-insured \\
\hline \multicolumn{5}{|l|}{2011} \\
\hline Outpatient OOPE (Yuan) & 475 & 70 & -44 & 3 \\
\hline Outpatient cost sharing (\%) & 68 & 2 & 19 & 22 \\
\hline Inpaitent OOPE (Yuan) & 5706 & -890 & -974 & -1556 \\
\hline Inpatient cost sharing (\%) & 44 & 23 & 30 & 47 \\
\hline \multicolumn{5}{|l|}{2013} \\
\hline Outpatient OOPE (Yuan) & 445 & 101 & 103 & 133 \\
\hline Outpatient cost sharing (\%) & 51 & 10 & 34 & 45 \\
\hline Inpaitent OOPE (Yuan) & 5454 & 15,501 & -407 & 918 \\
\hline Inpatient cost sharing (\%) & 48 & 18 & 17 & 51 \\
\hline \multicolumn{5}{|l|}{2015} \\
\hline Outpatient OOPE (Yuan) & 813 & 29 & -12 & 124 \\
\hline Outpatient cost sharing (\%) & 61 & 27 & 23 & 28 \\
\hline Inpaitent OOPE (Yuan) & 6562 & -516 & -957 & -1984 \\
\hline Inpatient cost sharing (\%) & 44 & 15 & 23 & 46 \\
\hline
\end{tabular}

OOPE Out-of-pocket expenditure, UEBMI Urban Employee Basic Medical Insurance, URBMI Urban Resident Basic Medical Insurance, NCMS New Rural Cooperative Medical Scheme

\section{Abbreviations}

GDP: Gross domestic product; NCD: Non-communicable diseases; NCMS: New cooperative medical scheme; OOPE: Out-of-pocket payment; UEBMI: Urban employee basic medical insurance; URBMI: Urban resident basic medical insurance

\section{Acknowledgements}

Not applicable.

\section{Authors' contributions}

VMQ and JTL conceived the study. VMQ conducted the data analysis and wrote the manuscript. YTZ, EH and JTL helped on editing the manuscript. YTZ, KSC, BM, YZ, HL and JTL critically commented on the revision and approved the final version. The author(s) read and approved the final manuscript.

\section{Funding}

This research received no specific grant from any funding agency in the public, commercial or not-for-profit sectors.

\section{Availability of data and materials}

The datasets supporting the conclusions of this article are publicly available in the CHARLS website: http://charls.pku.edu.cn/index.html

\section{Declarations}

\section{Ethics approval and consent to participate}

CHARLS was approved by the Ethical Review Committee (IRB) at Peking University, Beijing, China. All participants were required to provide written informed consent

\section{Consent for publication}

Not applicable.

\section{Competing interests}

Not applicable.

\section{Author details}

'Saw Swee Hock School of Public Health, National University of Singapore, Singapore, Singapore. ${ }^{2}$ Melbourne Institute, Applied Economic \& Social Research, Faculty of Business and Economics, University of Melbourne,
Melbourne, Victoria, Australia. ${ }^{3}$ Nossal Institute for Global Health, School of Population and Global Health, University of Melbourne, Melbourne, Victoria, Australia. ${ }^{4}$ Centre for Health Policy, School of Population and Global Health University of Melbourne, Melbourne, Victoria, Australia. ${ }^{5}$ Public Health Policy Evaluation Unit, Department of Primary Care and Public Health, School of Public Health, Imperial College London, London, UK.

Received: 11 January 2021 Accepted: 25 May 2021

Published online: 19 June 2021

\section{References}

1. Moreno-Serra R, Smith PC. Does progress towards universal health coverage improve population health? Lancet. 2012;380(9845):917-23. https://doi.org/1 0.1016/S0140-6736(12)61039-3.

2. Tangcharoensathien V, Mills A, Palu T. Accelerating health equity: the key role of universal health coverage in the sustainable development goals. BMC Med. 2015;13(1):101. https://doi.org/10.1186/s12916-015-0342-3.

3. Etienne C, Asamoa-Baah A, Evans DB, World Health Organization. The world health report: health systems financing: the path to universal coverage. Geneva: World Health Organization; 2010.

4. Reeves A, Gourtsoyannis Y, Basu S, McCoy D, McKee M, Stuckler D. Financing universal health coverage-effects of alternative tax structures on public health systems: cross-national modelling in 89 low-income and middle-income countries. Lancet. 2014;386(9990):274-80.

5. Hsiao W, Li M, Zhang S. Universal health coverage: the case of China in: UNRISD Working Paper 2014-15; 2014.

6. Asante A, Price J, Hayen A, Jan S, Wiseman V. Equity in health care financing in low- and middle-income countries: a systematic review of evidence from studies using benefit and financing incidence analyses. PLoS One. 2016; 11(4):e0152866. https://doi.org/10.1371/journal.pone.0152866.

7. Arsenault $C$, Jordan $K$, Lee D, Dinsa G, Manzi F, Marchant T, et al. Equity in antenatal care quality: an analysis of 91 national household surveys. Lancet Glob Health. 2018;6(11):e1186-95. https://doi.org/10.1016/S2214-109X(18)3 0389-9.

8. Irvine L, Elliott L, Wallace $\mathrm{H}$. Closing the health inequalities gap: an international perspective; 2005.

9. Barber SL, Yao L. Health insurance systems in China: A briefing note. In: World Health Report, Background Paper, No 37; 2010.

10. Meng Q, Yang H, Chen W, Sun Q, Liu X. People's Republic of China health system review: WHO regional office for the western pacific; 2015. 
11. Meng Q, Fang H, Liu X, Yuan B, Xu J. Consolidating the social health insurance schemes in China: towards an equitable and efficient health system. Lancet. 2015;386(10002):1484-92. https://doi.org/10.1016/S0140-673 6(15)00342-6.

12. Fang $\mathrm{H}$, Eggleston $\mathrm{K}$, Hanson $\mathrm{K}, \mathrm{Wu} \mathrm{M}$. Enhancing financial protection under China's social health insurance to achieve universal health coverage. BMJ. 2019;365:12378.

13. Huang $X$. Four worlds of welfare: understanding subnational variation in Chinese social health insurance. China Q. 2015;222:449-74. https://doi.org/1 $0.1017 /$ S0305741015000399.

14. National Bureau of Statistics of China. China Statistical Yearbook 2019. Beijing: National Bureau of Statistics of China; 2019.

15. Wagstaff A, Flores G, Hsu J, Smitz M-F, Chepynoga K, Buisman LR, et al. Progress on catastrophic health spending in 133 countries: a retrospective observational study. Lancet Glob Health. 2018;6(2):e169-79. https://doi.org/1 0.1016/S2214-109X(17)30429-1.

16. Wagstaff A, Neelsen S. A comprehensive assessment of universal health coverage in 111 countries: a retrospective observational study. Lancet Glob Health. 2020;8(1):e39-49. https://doi.org/10.1016/S2214-109X(19)30463-2.

17. Zhao Y, Oldenburg B, Mahal A, Lin Y, Tang S, Liu X. Trends and socioeconomic disparities in catastrophic health expenditure and health impoverishment in China: 2010 to 2016. Tropical Med Int Health. 2020;25(2): 236-47. https://doi.org/10.1111/tmi.13344.

18. Li Y, Wu Q, Xu L, Legge D, Hao Y, Gao L, et al. Factors affecting catastrophic health expenditure and impoverishment from medical expenses in China: policy implications of universal health insurance. Bull World Health Organ. 2012;90(9):664-71. https://doi.org/10.2471/BLT.12.102178.

19. Sun J, Lyu S. The effect of medical insurance on catastrophic health expenditure: evidence from China. Cost Eff Resour Alloc. 2020;18(1):10 https://doi.org/10.1186/s12962-020-00206-y.

20. Xu Y, Ma J, Wu N, Fan X, Zhang T, Zhou Z, et al. Catastrophic health expenditure in households with chronic disease patients: a pre-post comparison of the new health care reform in Shaanxi Province, China. Plos one. 2018;13(3):e0194539. https://doi.org/10.1371/journal.pone.0194539.

21. Barber SL, Huang B, Santoso B, Laing R, Paris V, Wu C. The reform of the essential medicines system in China: a comprehensive approach to universal coverage. J Glob Health. 2013;3(1):010303. https://doi.org/10.7189/ jogh.03.010303.

22. Fu W, Zhao S, Zhang Y, Chai P, Goss J. Research in health policy making in China: out-of-pocket payments in healthy China 2030. BMJ. 2018;360:k234

23. Zhang C, Lei $X$, Strauss J, Zhao Y. Health insurance and health care among the mid-aged and older Chinese: evidence from the National Baseline Survey of CHARLS. Health Econ. 2017;26(4):431-49. https://doi.org/10.1002/hec.3322.

24. Pan Y, Chen S, Chen M, Zhang P, Long Q, Xiang L, et al. Disparity in reimbursement for tuberculosis care among different health insurance schemes: evidence from three counties in Central China. Infect Dis Poverty 2016;5(1):7. https://doi.org/10.1186/s40249-016-0102-4.

25. You X, Kobayashi Y. Determinants of out-of-pocket health expenditure in China: analysis using China health and nutrition survey data. Appl Health Econ Health Policy. 2011;9(1):39-49. https://doi.org/10.2165/11530730000000000-00000

26. Zhao Y, Hu Y, Smith JP, Strauss J, Yang G. Cohort profile: the China health and retirement longitudinal study (CHARLS). Int J Epidemiol. 2014;43(1):618. https://doi.org/10.1093/ije/dys203.

27. Yang M. Demand for social health insurance: evidence from the Chinese new rural cooperative medical scheme. China Econ Rev. 2018;52:126-35. https://doi.org/10.1016/j.chieco.2018.06.004.

28. Liu GG, Zhao Z. Urban employee health insurance reform and the impact on out-of-pocket payment in China. Int J Health Plann Manag. 2006;21(3): 211-28. https://doi.org/10.1002/hpm.846.

29. Duncan GJ, Daly MC, McDonough P, Williams DR. Optimal indicators of socioeconomic status for Health Research. Am J Public Health. 2002;92(7): 1151-7. https://doi.org/10.2105/AJPH.92.7.1151.

30. Li C, Young B-R, Jian W. Association of socioeconomic status with financial burden of disease among elderly patients with cardiovascular disease: evidence from the China health and retirement longitudinal survey. BMJ Open. 2018;8(3):e018703. https://doi.org/10.1136/bmjopen-2 017-018703.

31. Country classification [https://datahelpdesk.worldbank.org/knowledgebase/a rticles/906519-world-bank-country-and-lending-groups]. Accessed 17 Apr 2020
32. Regidor E. Measures of health inequalities: part 1. J Epidemiol Community Health. 2004;58(10):858-61. https://doi.org/10.1136/jech.2003.015347.

33. GDP deflator (base year varies by country) [https://data.worldbank.org/indica tor/NY.GDP.DEFL.ZS?locations=CN\&view=chart]. Accessed 17 Apr 2020

34. Strauss J, Hong H, Lei X, Li L, Park AFV, Yang L, et al. Health Care and Insurance Among the Elderly in China: Evidence from the CHAR LS Pilot. In: Aging in Asia: Findings from New and Emerging Data Initiatives. Washington: National Academies Press; 2012. p. 342-70.

35. Du J, Yang $X$, Chen M, Wang Z. Socioeconomic determinants of out-ofpocket pharmaceutical expenditure among middle-aged and elderly adults based on the China health and retirement longitudinal survey. BMJ Open. 2019;9(7):e024936. https://doi.org/10.1136/bmjopen-2018-024 936.

36. Meng Q, Xu L, Zhang Y, Qian J, Cai M, Xin Y, et al. Trends in access to health services and financial protection in China between 2003 and 2011: a cross-sectional study. Lancet. 2012;379(9818):805-14. https://doi.org/10.101 6/S0140-6736(12)60278-5.

37. Zhou Z, Gao J, Fox A, Rao K, Xu K, Xu L, et al. Measuring the equity of inpatient utilization in Chinese rural areas. BMC Health Serv Res. 2011;11(1): 201. https://doi.org/10.1186/1472-6963-11-201.

38. Hunger M, Schwarzkopf L, Heier M, Peters A, Holle R, Group KS. Official statistics and claims data records indicate non-response and recall bias within survey-based estimates of health care utilization in the older population. BMC Health Serv Res. 2013;13(1):1-1. https://doi.org/10.1186/14 72-6963-13-1.

39. Lu C. Limitations of methods for measuring out-of-pocket and catastrophic private health expenditures. Bull World Health Organ. 2009;87(3):238-44 https://doi.org/10.2471/BLT.08.054379.

40. Qian D, Pong RW, Yin A, Nagarajan KV, Meng Q. Determinants of health care demand in poor, rural China: the case of Gansu Province. Health Policy Plan. 2009;24(5):324-34. https://doi.org/10.1093/heapol/ czp016.

41. Yip WC, Wang H, Liu Y. Determinants of patient choice of medical provider: a case study in rural China. Health Policy Plan. 1998;13(3):311-22. https://doi. org/10.1093/heapol/13.3.311

42. Shan-shan J, Li-zheng S, Ai-tian Y. Research on the Reimbursement Policy Effect of Chronic Diseases under New Rural Cooperative Medical System: Empirical analysis based on difference-in-differences model (in Chinese). Chinese Health Economics. 2013;32(9):56-8.

43. Miao Y, Gu J, Zhang L, He R, Sandeep S, Wu J. Improving the performance of social health insurance system through increasing outpatient expenditure reimbursement ratio: a quasi-experimental evaluation study from rural China. Int J Equity Health. 2018;17(1):89. https://doi.org/10.1186/s12939-0180799-8.

44. Zhang X, Wu Q, Liu G, Li Y, Gao L, Guo B, et al. The effect of the National Essential Medicines Policy on health expenditures and service delivery in Chinese township health centres: evidence from a longitudinal study. BMJ Open. 2014;4(12):e006471. https://doi.org/10.113 6/bmjopen-2014-006471.

45. Li Q, Chen F, Yang M, Lu L, Pan J, Li X, et al. The effect of China's National Essential Medicine Policy on health expenses: evidence from a National Study. Inquiry. 2018;55:46958018787057.

46. Ma J, Xu J, Zhang Z, Wang J. New cooperative medical scheme decreased financial burden but expanded the gap of income-related inequity: evidence from three provinces in rural China. Int J Equity Health. 2016;15(1):72. https://doi.org/10.1186/s12939-016-0361-5.

47. Myint C-Y, Pavlova M, Thein K-N-N, Groot W. A systematic review of the health-financing mechanisms in the Association of Southeast Asian Nations countries and the People's Republic of China: lessons for the move towards universal health coverage. PLoS One. 2019; 14(6):e0217278. https://doi.org/10.1371/journal.pone.0217278.

48. Qingyue M, Liying J, Beibei Y. Cost-sharing mechanisms in health insurance schemes: a systematic review: The Alliance for Health Policy and Systems Research, WHO; 2011.

49. Organization WBaWH. Healthy China : deepening health reform in China:a: building high-quality and value-based service delivery. Washington, DC: World Bank; 2019.

50. Yip W, Fu H, Chen AT, Zhai T, Jian W, Xu R, et al. 10 years of healthcare reform in China: progress and gaps in universal health coverage. Lancet. 2019;394(10204):1192-204. https://doi.org/10.1016/S0140-6736(1 9)32136-1. 
51. Liu M, Zhang Q, Lu M, Kwon C-S, Quan H. Rural and urban disparity in health services utilization in China. Med Care. 2007;45(8):767-74. https://doi. org/10.1097/MLR.0b013e3180618b9a.

52. Ta Y, Zhu Y, Fu H. Trends in access to health services, financial protection and satisfaction between 2010 and 2016: has China achieved the goals of its health system reform? Soc Sci Med. 2020;245:112715. https://doi.org/10.1 016/j.socscimed.2019.112715.

\section{Publisher's Note}

Springer Nature remains neutral with regard to jurisdictional claims in published maps and institutional affiliations.

Ready to submit your research? Choose BMC and benefit from:

- fast, convenient online submission

- thorough peer review by experienced researchers in your field

- rapid publication on acceptance

- support for research data, including large and complex data types

- gold Open Access which fosters wider collaboration and increased citations

- maximum visibility for your research: over $100 \mathrm{M}$ website views per year

At $\mathrm{BMC}$, research is always in progress.

Learn more biomedcentral.com/submissions 